\title{
USING HEALTH TECHNOLOGY ASSESSMENT TO SUPPORT OPTIMAL USE OF TECHNOLOGIES IN CURRENT PRACTICE: THE CHALLENGE OF "DISINVESTMENT"
}

Chris Henshall

University of York

email: consulting@chrishenshall.co.uk

Tara Schuller

Health Technology Assessment International Secretariat
Logan Mardhani-Bayne

Health Technology Assessment International Secretariat

On behalf of the HTAi Policy Forum

Background: Health systems face rising patient expectations and economic pressures; decision makers seek to enhance efficiency to improve access to appropriate care. There is international interest in the role of HTA to support decisions to optimize use of established technologies, particularly in "disinvesting" from low-benefit uses.

Methods: This study summarizes main points from an HTAi Policy Forum meeting on this topic, drawing on presentations, discussions among attendees, and an advance background paper. Results and Conclusions: Optimization involves assessment or re-assessment of a technology, a decision on optimal use, and decision implementation. This may occur within a routine process to improve safety and quality and create "headroom" for new technologies, or ad hoc in response to financial constraints. The term "disinvestment" is not always helpful in describing these processes. HTA contributes to optimization, but there is scope to increase its role in many systems. Stakeholders may have strong views on access to technology, and stakeholder involvement is essential. Optimization faces challenges including loss aversion and entitlement, stakeholder inertia and entrenchment, heterogeneity in patient outcomes, and the need to demonstrate convincingly absence of benefit. While basic HTA principles remain applicable, methodological developments are needed better to support optimization. These include mechanisms for candidate technology identification and prioritization, enhanced collection and analysis of routine data, and clinician engagement. To maximize value to decision makers, HTA should consider implementation strategies and barriers. Improving optimization processes calls for a coordinated approach, and actions are identified for system leaders, HTA and other health organizations, and industry.

Keywords: Disinvestment, Technology assessment, Biomedical, Coverage, Reimbursement

Health systems around the world are facing rising patient expectations at a time of increasing economic pressure, and decision makers are seeking to enhance system efficiency to allow improved access to care that is effective, safe, and offers worthwhile benefit (22). There is, therefore, increasing interest in approaches to optimize the use of technologies currently in the health system, including by reducing or "disinvesting" from uses that offer little or no benefit.

Health technology assessment (HTA) provides evidence to support decisions about the introduction and use of health technology. With greater emphasis on value for money in constrained economies, there is growing international interest in defining and enhancing the role of HTA to support decisions aiming to optimize the use of established health technologies.

The Health Technology Assessment International (HTAi) Policy Forum met in January 2012 in San Francisco, USA, to explore the use and role of HTA in these areas. The title of the meeting was "HTA and Disinvestment: Harnessing HTA to Reduce Lower Value or Ineffective Uses of Health Technologies".

The authors thank members and invited guests of the HTAi Policy Forum and members of the HTAi Board of Directors for their contributions to this paper, and acknowledge that funding to support development of this paper was provided by Health Technology Assessment International (HTAi).
Approaches to disinvestment vary by country and reimbursement system, and the Forum discussion aimed to identify key opportunities and challenges for applying HTA to support disinvestment, to consider barriers to the implementation of disinvestment decisions and how HTA can help to address these, and to discuss implications for the roles and work of existing HTA processes and bodies.

\section{METHODS}

\section{HTAi Policy Forum}

HTAi is the international professional society for producers and users of HTA (9). The HTAi Policy Forum provides an opportunity for leaders and senior management of for-profit and not-for-profit sector organizations with strategic interests in HTA to meet with invited experts for in-depth discussions about issues of emerging international interest (10). A detailed description of the HTAi Policy Forum can be found elsewhere (11).

\section{Development and Analysis of the Forum Discussion}

The topic of disinvestment was chosen by Forum members in June 2011. A background paper (available on the HTAi website 
(12)) and key publications were circulated to Forum members before the meeting. The Forum meeting ran from 22 to 24 January 2012 and included presentations and discussions between members and invited experts.

This study presents the authors' view of the main points arising from the meeting and areas of common thinking among participants. It has been informed by comments on drafts from those present, but it is not a consensus statement by Forum participants or their organizations. Supplementary Table 1, which can be viewed online at www.journals.cambridge.org/thc2012020, lists attendees of the San Francisco meeting.

\section{RESULTS}

\section{Contexts, Activities, and Terminology}

Members of the Policy Forum emphasized that the global economic crisis is having significant impacts on health systems, intensifying resource constraints and resulting in significant budget reductions in some countries. Systems are increasingly struggling to provide technologies of proven value to patients who can benefit from them. In this situation, the opportunity costs of continued use of technology that offers little or no worthwhile benefit can result in reduced access to technologies of proven benefit.

The Forum discussion distinguished between two general approaches to the review of technologies already in established use: (i) Routine review to identify and reduce lower value uses of technologies as part of a planned, ongoing process to improve quality and to create "headroom" for investment in new, highervalue technology use. (ii) Ad hoc review to identify uses of technologies that can be removed - temporarily or permanently - to respond to financial pressures, often at short notice and with little time for planning.

Both approaches may be used at the national, regional and local (e.g., a hospital) level. The case studies summarized below and recent literature reviews $(2 ; 8)$ show that HTA bodies and processes are already involved in routine review at various levels in systems around the world, but there is significant scope to increase the extent and profile of such activities and the role of HTA within them. HTA appears to play a much lesser role in ad hoc reviews and, although much of the Forum discussion focused on routine approaches, participants also saw the case for an increased role for HTA in ad hoc reviews to help to minimize any harmful effects on patients.

Given this range of contexts and activities, many at the meeting considered the term "disinvestment" to be unhelpful. "Disinvestment" may be seen to suggest the full withdrawal of a technology. It may also suggest withdrawal of resources from the system even when the goal may be reinvestment, and this can contribute to stakeholder resistance $(4 ; 24)$. The Forum, therefore, believed it more helpful to refer to the specific goals of optimization and to the three steps in the process: (i) Assessment or reassessment of technologies to determine their effectiveness, costs, and system demands and implications in relation to current alternatives (which may be different from those available when the technology was introduced); (ii) Decisions on optimal use (optimization) of technologies, based on the appraisal of evidence from one or more assessments and/or reassessments and other sources, in the light of the remit, values, priorities, and resources in a particular health system; (iii) Implementation of decisions to promote optimal use within the system through the provision of information for patients, clinicians, and the public; clinical guidelines, pathways, and decision support systems; quality standards; training; re-organization of staffing, equipment, and/or the estate; changes to coverage/reimbursement, etc.

\section{Key Stakeholder Perspectives}

The Forum considered the perspectives of key stakeholder groups to identify their objectives for participation in these processes and appropriate means of engagement. Participants presented summaries of the perspectives of key groups. While these differ in some ways, all agree that: (i) The objectives of optimization should include improving patient health outcomes, facilitating the introduction of technologies offering high value, and supporting health system sustainability. (ii) Active involvement of stakeholders at key points throughout identification, prioritization, reassessment, decision making, and implementation is necessary to identify target technologies and to secure support for optimization of use. (iii) (Re-)Assessments and decisions should be transparent and supported by robust evidence, and implementation should include appropriate knowledge transfer to all stakeholders.

The perspectives of each stakeholder group are summarized as follows.

Payer/Coverage Body Perspectives. Those responsible for payment/ coverage decisions have clear interests in optimizing technology use, but frequently find existing HTA and comparative effectiveness research (CER) reports to be of limited relevance to their decisions. Contributing factors include the length of reviews, the timing of assessments in relation to decision processes, the lack of economic analysis, and the failure to consider wider system impacts and implementation strategies. Payer/coverage bodies may also find it difficult to use reports not offering clear, scientifically robust guidance or recommendations, particularly in the face of clinical and patient resistance. Given these challenges, payer/coverage bodies may choose to leave hospitals and clinicians to make their own decisions about optimization and/or use other mechanisms to manage costs.

Patient and Public Perspectives. Patients exercise increasing influence over health systems and governments. Patients and patient groups are motivated primarily as consumers of health care and by what they perceive as the best interests of those with their condition. It is, therefore, important also to consider the perspective of the general public as the funder of health care, 
whether through taxation or insurance. It should be remembered that patients are also members of the wider public and can understand the need to limit access to technologies of little or no value to improve quality and control spending, and they can more readily accept disinvestment decisions or even become an ally in the process if it is open and transparent and they are actively involved from the outset. Negative reactions to full reduction or withdrawal of access to a technology may be moderated if patients who are able to benefit are still allowed access and if alternative treatment strategies are made available for others, or if the withdrawn technology can be accessed through other means, including private payment.

Clinician Perspectives. Clinicians' involvement in optimization of technology use is motivated by their wish to provide high quality patient care. This includes an understanding of the need to free up resources to invest in new technologies, but clinicians also see themselves as advocates of patients and their right to access treatments most appropriate to their needs. Clinicians develop views on the safety and effectiveness of technologies from their real-world professional experience. They are also front-line decision makers on the use of many technologies and themselves undertake optimization within their professional communities in response to emerging evidence, particularly of harm or ineffectiveness. Clinicians are, therefore, a key source of information for system-level reassessment processes, and key allies in making and implementing optimization decisions.

Industry Perspectives. Pharmaceutical and medical technology (medical devices and diagnostics) industry stakeholders support the optimization of technology use based on appropriate assessments where this improves system sustainability and quality and releases resources to invest in innovative and more effective treatments. Industry stakeholders do not, however, support disinvestment policies that remove products offering worthwhile benefits to certain patient sub-groups.

\section{Case Studies}

Forum members shared case studies of their experiences with reassessment and optimization. Table 1 summarizes four of these, selected for the variety of settings, challenges and strategic approaches they demonstrate.

\section{Challenges for Making and Implementing Decisions on Optimization}

Building on the material in the above case studies and other examples, the Forum considered the challenges involved in making and implementing decisions about technology optimization, particularly to reduce investment in and access to technologies. A range of implementation mechanisms can be adopted, for example, clinical practice guidelines, stakeholder education, changes in coverage or reimbursement, or decommissioning. These were discussed at the Forum meeting but are already well described in the literature $(3 ; 4 ; 7 ; 24)$ and are not, therefore, considered further here.
The Forum discussion identified four key challenges for making and implementing decisions on optimization. The first challenge is loss aversion and entitlement. There is a wellestablished literature on loss aversion $(15 ; 16)$, and its application to optimization decisions suggests that patients and clinicians tend to perceive greater disadvantage from a decision to remove access to an existing technology than they do from a decision to deny access to a new technology of similar value. Patients may also feel a sense of entitlement to technologies that have traditionally been available. Opposition to the removal of access to a technology is, therefore, frequently much stronger than an objective assessment of the value of the technology might suggest.

The second challenge is heterogeneity in patient outcomes. Outcomes for most technologies depend on several factors including patient characteristics. Even where a technology offers little or no demonstrable benefits for many patients, it may offer worthwhile benefits for some. Decisions on optimization need to reflect this and, where appropriate, allow continued access among individuals who can benefit from an established technology.

Third, professional and system inertia can present particular challenges. Clinicians trained to deliver existing technologies may see them as integral to their professional practice and identity. Clinical training and practice paradigms may be difficult to change, and organizations may have significant sunk costs in existing technology and/or supporting technologies and capital infrastructure.

The fourth challenge is the need for convincing evidence of absence of benefit from the use of a technology, or at least absence of harm from its withdrawal to overcome stakeholder resistance. Stronger evidence is often needed for decisions on reduction in use or disinvestment than for other aspects of technology use.

\section{Developing HTA Methods and Systems for Reassessment and Optimization}

Reassessment to inform decisions on the optimization of technologies in current use is no different in principle from the assessment earlier in the technology lifecycle to inform decisions on adoption. The principles and best practices of HTA that have been set out by various authorities $(1 ; 18)$ apply in all situations. Reassessments, however, need to recognize and address the challenges described above to meet decision maker needs.

The literature suggests that there are fewer candidate technologies for total removal from the system than some policy makers and commentators seem to assume, $(4 ; 7)$ and decision makers are reluctant to invest effort in reducing technology use unless the benefits of optimization are significant and optimization is likely to succeed. The challenge is to identify those areas of technology use that are neither "too small to matter" nor "too big to tackle", and where there is good potential for successful implementation. 
Table 1. Selected case studies of optimisation and/or disinvestment initiatives

\begin{tabular}{|c|c|c|c|}
\hline $\begin{array}{l}\text { Case study } \\
\text { organization }\end{array}$ & $\begin{array}{l}\text { Description of optimization/ } \\
\text { disinvestment process }\end{array}$ & Success features and challenges & Key lessons learned \\
\hline $\begin{array}{l}\text { A. Gemelli University } \\
\text { Hospital Rome, } \\
\text { Italy }\end{array}$ & $\begin{array}{l}\text { - Proactive Disinvestment Process (PDP) } \\
\text { linked to routine HTAs for new } \\
\text { technologies: clinicians identify medical } \\
\text { device for removal/reduced use } \\
\text { The case of surgical meshes: } \\
\text { - } 70+\text { different surgical meshes were } \\
\text { available } \\
\text { - Literature review, analysis of usage data, } \\
\text { and surgeons' perceptions converged to } \\
\text { recommend investing in light-weight } \\
\text { surgical meshes } \\
\text { - HTA unit issued a guideline for use of } \\
\text { light-weight meshes }\end{array}$ & $\begin{array}{l}\text { Success features: } \\
\text { - Use of guideline has led to } 65 \% \text { reduction in the use } \\
\text { of high weight meshes. } \\
\text { Challenges: } \\
\text { - Clinicians' habits } \\
\text { - Data collection, lack of evidence } \\
\text { - Administrative work (re-negotiation of contracts } \\
\text { with vendors) } \\
\text { - Time-consuming process }\end{array}$ & $\begin{array}{l}\text { - Clinicians engaged where they perceive } \\
\text { a benefit (improved patient care) } \\
\text { - Dedicated procedure is beneficial } \\
\text { (synergistic \& proactive part of routine } \\
\text { HTA procedures for new technology) } \\
\text { - Transparent criteria and } \\
\text { methodological rigour important }\end{array}$ \\
\hline CADTH Canada & $\begin{array}{l}\text { - Optimal use guidance for self-monitoring } \\
\text { of blood glucose would provide } \$ 450 M \\
\text { savings nationally compared to current } \\
\text { practice. } \\
\text { - No province (with authority for coverage } \\
\text { decisions in their jurisdictions) has yet } \\
\text { implemented the CADTH } \\
\text { recommendations. }\end{array}$ & $\begin{array}{l}\text { Success features: } \\
\text { - Early stakeholder involvement } \\
\text { - Strong methodology and robust recommendations } \\
\text { Challenges: } \\
\text { - Lengthy project } \\
\text { - Guidance insufficiently timed and adapted to local } \\
\text { processes }\end{array}$ & $\begin{array}{l}\text { - Knowledge transfer (KT) essential: } \\
\text { start early, work closely with clinical } \\
\text { community and policy makers, involve } \\
\text { champions, and target general public } \\
\text { - Be persistent but be patient - changes } \\
\text { take time }\end{array}$ \\
\hline $\begin{array}{l}\text { Haute Autorité de } \\
\text { Santé (HAS) } \\
\text { France }\end{array}$ & $\begin{array}{l}\text { - } 1999 \text { Ministerial decree requested } \\
\text { Transparency Committee to measure } \\
\text { "Service médical rendu" (real medical } \\
\text { value) of all reimbursed drugs by disease } \\
\text { severity and clinical effectiveness. } \\
\text { - 1999-2001: Conducted review and } \\
\text { recommended: } \\
\text { * } 840 \text { drugs for reduced coverage. } \\
\text { * } 835 \text { for delisting (all were re-assessed } \\
\text { in 2003, and total of } 322 \text { drugs delisted } \\
\text { from 2003-2008). }\end{array}$ & $\begin{array}{l}\text { Success features: } \\
\text { - } 322 \text { drugs of insufficient real medical value delisted. } \\
\text { Challenges: } \\
\text { - Changing political agenda delayed reassessment } \\
\text { and delisting. } \\
\text { - Entrenched stakeholder positions against delisting in } \\
\text { some cases of high utilization. }\end{array}$ & $\begin{array}{l}\text { - Health professional involvement is } \\
\text { critical to success. } \\
\text { - Must include broader scope of HTA } \\
\text { (particularly economic aspects). } \\
\text { - Importance of links/interface between } \\
\text { HTA agency and regulatory body } \\
\text { especially for re-assessing drugs. }\end{array}$ \\
\hline NICE United Kingdom & $\begin{array}{l}\text { March } 2008 \text { NICE issued guidance on } \\
\text { prophylaxis against infective endocarditis: } \\
\text { - Do not offer antibiotic prophylaxis against } \\
\text { infective endocarditis to people } \\
\text { undergoing dental procedures or } \\
\text { procedures in the gastrointestinal tract, } \\
\text { genitourinary tract or respiratory tract. } \\
\text { - Do not offer chlorhxidine mouthwash as } \\
\text { prophylaxis against infective endocarditis } \\
\text { to people at risk undergoing dental } \\
\text { procedures. }\end{array}$ & $\begin{array}{l}\text { Success features: } \\
\text { - NICE guidance led to approx. } 80 \% \text { reduction in total } \\
\text { number of prescriptions for antibiotic prophylaxis } \\
\text { over } 2 \text { years. } \\
\text { - Tracked health outcomes to show no post-guidance } \\
\text { change in trend for prevalence of infective } \\
\text { endocarditis. Reduction in prescriptions had no } \\
\text { impact on health outcomes. } \\
\text { Challenges: } \\
\text { - Criticized for not providing positive indications of } \\
\text { when to give antibiotics (only "do not do" } \\
\text { recommendations). }\end{array}$ & $\begin{array}{l}\text { - Important to demonstrate link between } \\
\text { reassessment decision and outcomes } \\
\text { (health, economic, etc.). } \\
\text { - Ongoing dialogue with stakeholders } \\
\text { key (incl. clinicians, professional } \\
\text { societies, financial staff) with clear } \\
\text { communication of evidence behind } \\
\text { decision. } \\
\text { - Strong leadership and political support. } \\
\text { - Broad communications and public } \\
\text { relations messaging for } \\
\text { implementation is important. }\end{array}$ \\
\hline
\end{tabular}


Table 2. Approaches and Criteria for Identification and Prioritization of Technologies (Informed by $5 ; 6 ; 13 ; 14 ; 23$ )

Identification and prioritization approaches

Potential criteria

\begin{tabular}{|c|c|}
\hline $\begin{array}{l}\text { Ongoing consultation with clinical speciality groups to identify and prioritize technologies } \\
\text { they believe to be misused and/or of no or little value and would support optimisation. } \\
\text { Using routine data to identify variations in use of technologies and/or associated } \\
\text { outcomes } \\
\text { Using routine data to identify technologies associated with high budget impact } \\
\text { Monitoring published studies and systematic reviews, to identify new evidence on } \\
\text { existing technologies and/or evidence that new technologies outperform existing } \\
\text { technologies and/or relevant evidence gaps } \\
\text { Routine identification of technology candidates for optimisation, e.g., all new HTAs for } \\
\text { technology introduction include identification of candidates for } \\
\text { optimisation/reassessment; or all technologies are identified as candidates for } \\
\text { reassessment x years after initial introduction or assessment } \\
\text { Feasibility assessment to support prioritization, e.g., identify barriers and opportunities in } \\
\text { order to select reassessment candidates with most potential for change and impact. }\end{array}$ & $\begin{array}{l}\text { Evidence from research, routine data or expert opinion regarding: } \\
\text { - Safety } \\
\text { - Efficacy } \\
\text { - Effectiveness } \\
\text { - Cost-effectiveness } \\
\text { - Disease burden and potential impact on health } \\
\text { - Budget impact } \\
\text { - Professional disagreement on appropriate use or value (as indicated by } \\
\text { expressed views and/or variations in use) } \\
\text { - Professional agreement on low value, obsolescence, waste or misuse } \\
\text { - Existence of alternative/superior/less expensive replacement technology } \\
\text { or treatment strategies } \\
\text { Feasibility criteria for prioritization include: } \\
\text { - Infrastructure for targeted data collection and analysis } \\
\text { - Engagement of internal and external stakeholders (particularly clinicians) } \\
\text { - Awareness of policy environment and political readiness for implementation } \\
\text { - Awareness of and approaches to overcome stakeholder perceptions of loss } \\
\text { and entitlement } \\
\text { - Presence of alternative technology or treatment strategies } \\
\text { - Funding to invest in alternative technology or strategies (where needed) } \\
\text { - Resources for KT for implementation } \\
\text { - Resources for monitoring impact }\end{array}$ \\
\hline
\end{tabular}

The appropriateness of mechanisms for identification and prioritization vary across jurisdictions, and several sets of prioritization criteria have been identified in published $(5 ; 13 ; 20)$ and grey literature $(21 ; 23)$ with a systematic approach now being developed in several jurisdictions, including Galicia and the Basque Country in Spain, and The Netherlands $(6 ; 14)$. The Forum discussion stressed the importance of early clinician involvement in this area, both as a means to identify and prioritize technologies to reassess and to create support for subsequent implementation of decisions. In addition, costs, burden of disease, health outcomes, and variations in use were used as criteria for the identification and prioritization of candidate technologies in case studies considered, although such data are not routinely available in all healthcare systems. Table 2 summarizes approaches and criteria to identify and prioritize technologies for reassessment.

As with any HTA, reassessment needs to balance depth and rigor with timeliness. This is a particular challenge for reassessments to support ad hoc decisions about reductions in technology provision to respond to budget cuts or shortfalls. Such decisions often require advice sooner than most formal HTA approaches can deliver. One solution may be for HTA functions or organizations to anticipate such demands by devel- oping an inventory of candidate technologies and preliminary reassessments that can be offered to decision makers when required. An international library of candidate technologies, reassessments, optimization decisions, implementation strategies, and outcomes from systems around the world highlighting challenges and success factors could also assist HTA organizations in responding efficiently to requests for rapid advice. HTA organizations may still, however, have to make difficult decisions about their involvement in such processes. On the one hand, their scientific credibility may be compromised if they are seen to offer advice on the basis of insufficient analysis. On the other, they risk losing the support of decision makers if they are not seen to be supporting difficult and important decisions about health technology use.

As noted previously, optimization often calls for stronger evidence than other decisions on technology use. Unfortunately, it is often more difficult to generate clear evidence on the extent (or lack of) benefits of established technologies than it is for new technologies. Randomized studies of technologies in routine use are not generally feasible, and even observational studies may be difficult to conduct. Assessments of technologies in routine use, therefore, frequently depend upon analysis of routine health system data. In many health systems, this 
requires: (i) Better systems to collect data on technology use and health outcomes in routine practice, with data on patient characteristics to allow sub-group analysis where needed. (ii) Better use and analysis of the data that is available. (iii) Ongoing discussions with clinical experts to identify candidate technologies for optimization, analyze their use and outcomes, interpret the data, and agree on and implement strategies to change use.

Given the challenges in developing clear evidence in advance, it is important to monitor health outcomes as use is scaled back or withdrawn. The case study in Table 1 from NICE in the UK showed how the monitoring of endocarditis rates in the general population helped to allay concerns that reduced use of prophylactic antibiotics for "at-risk" patients undergoing dental procedures might lead to an increase in endocarditis. In that example, monitoring was used to confirm an expected outcome. It would in theory also be possible to monitor outcomes as part of an experimental or phased withdrawal of a technology, to generate evidence to confirm the postulated lack of effectiveness to inform decisions about fuller withdrawal. Such an approach might be thought of as "managed exit" by analogy with recent approaches to "managed entry" $(17 ; 19)$.

Most definitions of HTA agree that assessments should consider system impacts and the social, ethical, and legal implications of a technology. These are particularly important in reassessment, given the challenges described above for decisions on optimization. To be of maximum value to decision makers, reassessments also need to identify possible barriers to optimization of a particular technology and offer advice on implementation strategies to address these.

Implementation strategies to be considered in this context include the following: (i) Allowing continued use for patients for whom a technology remains justified and providing alternative treatment strategies and/or access paths for others. (ii) Where possible, reinvesting some or all of any resources released in ways that will benefit patients with the same or similar condition or to improve care in the same clinical specialty area. (iii) Education and knowledge transfer for patients and clinicians about the reasons for the decision and the expected benefits. (iv) Incorporating the decision in clinical guidelines or pathways or decision support tools. (v) Financial incentives for clinicians and/or provider units. (vi) Changes to formularies and/or coverage/reimbursement listings.

The active involvement of patients, clinicians and the public in reassessment and decision making is essential to successful implementation. The importance of clinicians both as a source of intelligence on the use and outcomes of technologies in routine practice and as partners in implementation cannot be overstated.

\section{Actions to Improve Optimization Processes}

Various suggestions emerged from the Forum discussion for actions to improve the processes of reassessment, decision making and implementation of technology optimization. Many of these aim to enhance the role of HTA as part of a coherent approach to the planning and management of health systems. The key suggestions are summarized here.

Health system leaders, politicians, clinicians, HTA bodies, organizations, and experts, and industry should: Work together to explain to patients and the public the importance of reassessment and optimization to improve the safety, quality, efficiency, and sustainability of health care, and to free up resources for new technologies.

Health system leaders should: (i) Ensure they have processes and incentives in place for the ongoing reassessment and optimization of the use of health technologies, with clear and transparent governance arrangements and appropriate stakeholder involvement. (ii) Task and resource appropriate HTA systems and bodies to support optimization and the evaluation of impacts of this work as an integral part of their role, working in synergy with outcomes research, quality assessment/assurance/improvement, patient safety, and other relevant parts of the wider system. (iii) Draw on HTA expertise and advice when conducting ad hoc reviews of technology use in response to budgetary pressures.

HTA systems and bodies should: (i) Work with clinicians, patients, the public and industry in work to reassess and promote optimization of technologies in routine use. (ii) Work with decision makers to identify candidate technologies for reassessment and optimization using explicit criteria that reflect the potential for beneficial change in use. (iii) Where possible, anticipate requests for advice on technology optimization and be ready to respond quickly when needed. (iv) Use assessment methods that strike an appropriate balance between rigor and speed, taking account of the specific challenges described above. (v) Recognize that decision makers may need advice on potential barriers to implementation and strategies to overcome these, in addition to advice on optimal use of a technology. (vi) Work with clinicians, relevant experts, and managers to improve the methods and infrastructure for reassessment of established technologies. (vii) Work with decision makers to develop a coherent and robust approach to identifying technologies for reassessment, making decisions on optimization, implementing and monitoring the impact of those decisions on technology use and health outcomes, and making adjustments as appropriate in the light of data collected - a "Managed Exit" approach.

HTAi and other international and national HTA organizations (including INAHTA, EUnetHTA, and Euroscan) should: (i) Promote, support, and disseminate work to improve methods and tools for reassessment, evidence-based decision making and implementation strategies to promote optimal use of technologies in routine use. (ii) Promote the value of HTA across the full technology lifecycle. (iii) Develop an inventory of practical approaches in systems around the world for prioritization, reassessment, decision making, and implementation of technology optimization. (iv) Develop a library of reassessment 
reports and recommendations, optimization decisions, implementation strategies, and outcomes from systems around the world.

\section{CONCLUSION}

Processes for identifying technologies for reassessment, undertaking those reassessments, and making and implementing decisions on optimal use are complex and vary according to the circumstances and challenges of particular health system contexts. HTA has a key role to play in promoting and supporting an evidence-based approach to technology optimization to improve safety, quality, and appropriate use of resources. To achieve this, HTA bodies and systems need to work closely with clinicians, other stakeholders, decision makers, and other parts of the healthcare system. As with other applications of HTA, there are important opportunities for organizations to learn from each other's work and experience, and a need for international collaboration to share information and to develop and disseminate methods and good practice. It is hoped that the Forum meeting and this study will help to promote such developments.

\section{SUPPLEMENTARY MATERIAL}

Supplementary Table 1

www.journals.cambridge.org/thc2012020

\section{CONTACT INFORMATION}

Chris Henshall, PhD, HTAi Policy Forum Chair and Honorary Fellow, (consulting@chrishenshall.co.uk), Centre for Health Economics, University of York

Tara Schuller, MA, Manager of Policy Programs, Health Technology Assessment International Secretariat

Logan Mardhani-Bayne, BA (Hons), Managing Director, Health Technology Assessment International Secretariat

\section{CONFLITS OF INTEREST}

Chris Henshall has received funding from HTAi for the work reported in this paper, and consultancy fees from several medical companies for chairing Advisory Boards on specific technologies and advice on global HTA developments and strategy. Tara Schuller and Logan Mardhani-Bayne are employed at Health Technology Assessment International.

\section{REFERENCES}

1. Busse R, Orvain J, Velasco M, et al. Best practice in undertaking and reporting health technology assessments. Working group 4 report. Int $J$ Technol Assess Health Care. 2002;18:361-422.

2. Centre for Health Economics Research and Education. Reducing the use of ineffective health care interventions. CHERE Report for NSW Treasury. 2010. Working Paper 2010/5. http://www.chere.uts.edu.au/ pdf/wp2010_5.pdf (accessed January 15, 2012).
3. Elshaug A, Hiller J, Tunis SR, Moss JR. Challenges in Australian policy processes for disinvestment from existing, ineffective health care practices. Aust New Zealand Health Policy. 2007;4:23.

4. Elshaug A, Hiller JE, Moss JR. Exploring policy makers' perspectives on disinvestment from ineffective healthcare practices. Int J Technol Assess Health Care. 2008;24:1-9.

5. Elshaug A, Moss JR, Littlejohns P, et al. Identifying existing health care services that do not provide value for money. Med J Aust. 2009;190:269273.

6. Galician Agency for HTA. Avalia-T. PriTec tool for obsolete heath technologies. http://pritectools.es/Controlador/documentosAction.php (accessed January 28, 2012).

7. Garner S, Littlejohns P. Disinvestment from low value clinical interventions: NICEly done? BMJ. 2011;343:d4519.

8. Gerdvilaite J, Nachtnebel A. Disinvestment. Overview of disinvestment experiences and challenges in selected countries. HTA-Projektbericht 57, Ludwig Boltzmann Institut; 2011.

9. Health Technology Assessment International (HTAi). http://www.htai.org (accessed February 2012).

10. Health Technology Assessment International (HTAi). Policy forum. http://www.htai.org/index.php?id=643 (accessed February 2012).

11. Henshall C. The HTAi Policy Forum: Promoting public-private sector dialogue on the development and use of HTA in health system decision making. Michael Q. 2012;9:157-164.

12. HTAi Secretariat and Policy Forum Committee. HTAi Policy Forum Meeting 2012: HTA and Disinvestment: Harnessing HTA to reduce lower value or ineffective uses of health technologies. Background Paper. January 2012. http://www.htai.org/fileadmin/HTAi_Files/Policy_Forum_ Public/HTAi_Policy_Forum_2012_Background_Paper.pdf (accessed February 2012).

13. Ibargoyen-Roteta N, Gutierrez-Ibarluzea I, Asua J, et al. Scanning the horizon of obsolete technologies: Possible sources for their identification. Int J Technol Assess Health Care. 2009;25:249-254.

14. Ibargoyen-Roteta N, Gutiérrez-Ibarluzea I, Asua J. 2009. Report on the development of the GuNFT Guideline. Guideline for Not Funding existing health Technologies in health care systems. Quality Plan for the NHS of the MHSP. Basque Office for Health Technology Assessment (Osteba). Health Technology Assessment Reports: OSTEBA N ${ }^{\circ}$ 2007/11. http://www9.euskadi.net/sanidad/osteba/datos/e_10_11_report_GuNFT. pdf (accessed November 18, 2011).

15. Kahneman D, Tversky A. Prospect theory: An analysis of decision under risk. In: Kahneman D, Tversky A, eds. Choices, values, and frames. Cambridge, UK: Cambridge University Press; 2000:17-43. (reprinted from Econometrica 47; 2. 1979;263-291).

16. Kahneman D. Prospect theory. In: Thinking, fast and slow. New York: Farrar, Krause, and Giroux; 2011:278-288.

17. Klemp M, Frønsdal KB, Facey K. What principles should govern the use of managed entry agreements? Int J Technol Assess Health Care. 2011;27:77-83.

18. Kristenden FB, Sigmund H, eds. Health Technology Assessment Handbook. 2nd ed. Copenhagen: Danish Centre for Evaluation and Health Technology Assessment, National Board of Health; 2007. http://www. sst.dk/publ/Publ2008/MTV/Metode/HTA_Handbook_net_final.pdf (accessed February 23, 2012).

19. McCabe CJ, Stafinski T, Edlin R, Menon D. Banff AED Summit. Access with evidence development schemes: A framework for description and evaluation. Pharmacoeconomics. 2010;28:143-152.

20. Mitton C, Dionne F, Damji R, et al. Difficult decisions in times of constraint: Criteria based Resource Allocation in the Vancouver Coastal Health Authority. BMC Health Serv Res. 2011;11:169.

21. Mørland B. Using HTAs to support disinvestment - the case of sleep apnoea (OSAS) in Norway. Power Point presentation from the 27th 
Henshall et al.

Conference of the International Society for Quality in Health Care. 2010.

22. Porter ME. What is value in health care? N Engl J Med. 2010;363:24772481.

23. Ruano Raviña A, Velasco González M, Varela Lema L, et al. 2007. Identification, prioritisation and assessment of obsolete health technologies. A methodological guideline Quality Plan for the National Health
System. Galician Agency for Health Technology Assessment, AvaliaT. http://www.sergas.es/docs/Avalia-t/ObsoleteTechMemFinal.pdf (accessed November 18, 2011).

24. Wulff KC, Miller FG, Pearson SD. Can coverage be rescinded when negative trial results threaten a popular procedure? The ongoing saga of vertebroplasty. Health Aff (Millwood). 2011;30:22692276 . 